ARTIKEL PENELITIAN

\title{
Kesesuaian ukuran kanalis spinalis lumbal berdasarkan Ultrasonografi dengan MR-Myelografi pada penderita nyeri punggung bawah
}

\author{
Emilya Jufianti ${ }^{1}$, Muhammad Ilyas ${ }^{1}$, Bachtiar Murtala ${ }^{1}$, Andi Alfian Zainuddin ${ }^{2}$, Cahyono \\ Kaelan ${ }^{3}$, Mirna Muis ${ }^{1}$ \\ 1. Bagian Radiologi, Fakultas Kedokteran, Universitas Hasanuddin, Makassar; 2. Bagian IKM, \\ Fakultas Kedokteran, Universitas Hasanuddin, Makassar; 3. Bagian Neurologi, Fakultas Kedokteran, \\ Universitas Hasanuddin, Makassar
}

Korespondensi: Emilya Jufianti; e-mail: emilyajufianti@yahoo.com

\begin{abstract}
Abstrak
Tujuan: Penelitian ini bertujuan menilai kesesuaian ukuran kanalis spinalis lumbal berdasarkan ultrasonografi dengan MR myelografi lumbosakral pada penderita Nyeri Punggung Bawah (NPB). Metode: Penelitian ini menggunakan desain observasi cross-sectional dan dilakukan di Bagian Radiologi RSUP Dr. Wahidin Sudirohusodo Makassar dari November 2018 - Februari 2019. Sampel penelitian sebanyak 54 dengan 22 sampel eksklusi dan 32 sampel inklusi. Dari 32 sampel pada level L3-L4 sebanyak 27 sampel normal dan 5 sampel stenosis, level L4-L5 sebanyak 21 sampel normal dan 11 sampel stenosis, level L5-S1 sebanyak 28 sampel normal dan 4 sampel stenosis. Data dianalisis dengan analisis statistik melalui uji korelasi Person. Hasil: Hasil penelitian menunjukkan terdapat kesesuaian ukuran kanalis spinalis lumbal berdasarkan ultrasonografi dengan MR myelografi lumbosakral pada penderita NPB pada level L3-L4 dengan nilai $p=0,001(<0,05)$ dan memiliki kekuatan hubungan kuat dengan nilai $r=0,985$. Data juga menunjukkan bahwa terdapat kesesuaian antara hasil MR myelografi dengan Ultrasonografi lumbosakral pada level L4-L5 dengan nilai $p=0,001(<0,05)$ dan memiliki kekuatan hubungan kuat dengan nilai $r=0,987$. Data juga menunjukkan bahwa terdapat kesesuaian antara hasil MR myelografi dengan Ultrasonografi lumbosakral pada level L5-S1 dengan nilai $p=0,001(<0,05)$ dan memiliki kekuatan hubungan kuat dengan nilai $r=0,973$. Simpulan: Terdapat kesesuaian ukuran kanalis spinalis lumbal berdasarkan ultrasonografi dengan MR myelografi lumbosakral pada penderita NPB.
\end{abstract}

Kata kunci: nyeri punggung bawah; kanalis spinalis lumbal; ultrasonografi; MRI-MR myelografi

\section{Abstract}

Objectives: This study aims to find out compatibility the size of lumbar spinal canal based on ultrasonography and MR lumbosacral myelography in Low Back Pain (LBP). Methods: This research used cross-sectional observation design and was conducted in Radiology Unit of RSUP Wahidin Sudirohusodo, Makassar from November 2018 - February 2019. There were 54 samples consisting of 22 exclusive and 32 inclusive. Out of 32 samples, for L3-L4 27 normal and 5 stenosis; for L4-L5 21 normal and 4 stenosis; L5-S1 28 normal and 4 stenosis. The data were analyzed using Pearson correlation. Results: The results of the research indicate the compatibility between the size of lumbar spinal canal based on ultrasonography and MR myelography lumbosacral in LBP for L3-L4 with $p=0.001(<0.05)$ and it has a strong correlation with $r=0.985$. It is also indicated that there is a compatibility between the result of MR myelography and ultrasonography lumbosacral at $L 4-L 5$ with $p=0.001(<0.05)$ and it has a strong correlation with a value of $r=0.987$. There is also compatibility between the result of $M R$ myelography and ultrasonography lumbosacral at L5-S1 with $p=0.001 \quad(<0.05)$ and it has a strong 
correlation with $r=0.973$. Conclusions: There is compatibility for the lumbar spinal canal size based on ultrasonography with MR myelography lumbosacral in low back pain.

Keywords: low back pain; lumbar spinal canal; ultrasonography; MRI-MR myelography

\section{PENDAHULUAN}

Nyeri Punggung Bawah (NPB) adalah suatu sindrom klinik yang ditandai dengan gejala utama rasa nyeri didaerah tulang punggung bawah, dapat merupakan nyeri lokal maupun nyeri radikuler atau keduanya. NPB merupakan masalah yang banyak ditemukan dan sangat mengganggu kegiatan dan aktivitas seharihari, $60 \%-80 \%$ dari populasi di dunia pernah mengalami NPB terutama pada usia 35-55 tahun. NPB biasanya bersifat akut bila gejalanya kurang dari 6 minggu, sub-akut 6-12 minggu dan kronis lebih dari 12 minggu. $1,2,3$

Penyebab utama nyeri punggung bawah adalah akibat penyebab mekanik, salah satunya yaitu stenosis spinalis. Stenosis kanal lumbal merupakan penyempitan osteoligamentous kanalis vertebralis dan atau foramen intervertebralis yang menghasilkan penekanan pada akar saraf sumsum tulang belakang. Kanalis vertebral tubular berisi sumsum tulang belakang, meninges, akar saraf tulang belakang, dan pembuluh darah yang menyuplai tali pusat, meninges, vertebra, sendi, otot, dan ligamen. Gejala yang dirasakan tiap pasien berbeda tergantung pola dan distribusi stenosis. Gejala bisa berhubungan dengan satu akar saraf pada satu level berupa nyeri punggung bawah, nyeri ekstremitas bawah dan kelemahan. ${ }^{4-6}$

Lumbar spinal stenosis menjadi salah satu masalah yang sering ditemukan yang merupakan penyakit degeneratif pada tulang belakang pada populasi usia lanjut. Prevalensinya 5 dari 1000 orang di atas usia 50 tahun. Merupakan penyakit terbanyak yang menyebabkan bedah pada tulang belakang pada usia lebih dari 60 tahun. Patofisiologi-nya tidak berkaitan dengan ras, jenis kelamin, tipe tubuh, pekerjaan dan paling banyak mengenai lumbar ke-4-5 dan ke-3-4.

Peningkatan kejadian NPB telah dilaporkan dalam beberapa tahun terakhir. Imaging memainkan peran penting dalam diagnosis penyebab NPB. Missere et al melaporkan sensitivitas $84 \%$ dan spesifikasi $60 \%$ untuk ultrasonografi transabdominal dalam mendiagnosis NPB dengan nilai cut off diameter spinal $14 \mathrm{~mm}$. CT scan lebih jelas menunjukkan tanda-tanda degenerative disc disease. MRI-MR myelografi suatu tindakan non-invasif yang dapat memberikan informasi mengenai ruang subarachnoid. Sedangkan foto polos lumbosakral merupakan penilaian rutin untuk pasien dengan back pain. ${ }^{9-12}$

Verbiest (1954) adalah yang pertama kali menunjukkan perkembangan dari kanalis spinalis yang sempit. Pasien-pasien dengan operasi diskus ditemukan memiliki kanal lumbar yang lebih sempit. ${ }^{13}$

Diameter AP normal kanalis spinalis lumbar bervariasi antara 15-27 $\mathrm{mm}$. Diameter kurang dari $10 \mathrm{~mm}$ dipastikan 
suatu stenosis. Hulagu Kaptan dkk melaporkan pada pasien-pasien yang kanalis spinalis lumbal dengan diameter anteroposterior kurang dari 11,5 mm, dipastikan stenosis kanalis spinalis lumbal, dan laminektomi total lebih sering dilakukan. ${ }^{14,15}$

Karena pentingnya peranan imaging dalam diagnosis nyeri punggung bawah, kami tertarik untuk meneliti kesesuaian ukuran kanalis spinalis lumbal menggunakan ultrasonografi dengan MR-myelografi lumbosakral pada penderita nyeri punggung bawah.

\section{METODE}

Penelitian ini merupakan suatu studi observasional dengan desain crosssectional untuk mengetahui kesesuaian ukuran kanalis spinalis lumbal berdasarkan ultrasonografi dan MR myelografi lumbosakral di Instalasi Radiologi Sentral RSUP dr. Wahidin Sudirohusodo, Makassar mulai bulan November 2018 sampai Februari 2019 untuk mengumpulkan sampel.

Populasi pada penelitian ini adalah semua penderita Nyeri Punggung Bawah (NPB) yang dikirim oleh klinisi untuk pemeriksaan MRI-MR myelografi lumbosakral di instalasi radiologi sentral RSUP dr. Wahidin Sudirohusodo, Makassar mulai bulan November 2018 sampai Februari 2019. Besar sampel minimal adalah 32 orang.

Sampel pada penelitian ini adalah bagian dari populasi yang sesuai dengan kriteria inklusi : (1) Semua penderita yang datang ke Instalasi Radiologi sentral RSUP $d r$. Wahidin Sudirohusodo, Makassar dengan keluhan nyeri punggung bawah untuk melakukan MRI-MR myelografi lumbosacral, (2) Umur 30 - 60 tahun, (3) Keadaan umum baik dan dapat menjalani pemeriksaan USG, (4) Bersedia mengikuti prosedur penelitian dengan mengisi informed concent, dan kriteria eksklusi: (1) Keadaan umum pasien tidak memungkinkan untuk dilakukan pemeriksaan USG lumbosakral; (2) Atlet olahraga (yang melakukan aktivitas olahraga minimal empat kali seminggu); (3) Pekerja berat; (4) Pernah menjalani operasi tulang belakang; (5) Riwayat trauma pada tulang belakang; (6) Kelainan perkembangan/skoliosis; (7) Kelainan kongenital tulang belakang; (8) Infeksi pada tulang belakang; (9) Tumor pada tulang belakang; (10) Pasien dengan tetraparese dan paraparese; Mempunyai riwayat urolith; Mempunyai riwayat massa ginekologi.

Dilakukan pendataan identitas pasien yang memenuhi kriteria penelitian dan memberikan penjelasan lengkap tentang pemeriksaan yang akan dilakukan, maksud, tujuan dan kegunaan penelitian. Setelah pasien menyetujui kemudian pasien menjalani pemeriksaan MRI-MR myelografi lumbosakral, jarak antara dua margin thecal sac level CV L3-L4, L4-L5 dan L5-S1 diukur pada potongan sagittal. Kemudian pasien menjalani pemeriksaan USG lumbosakral, posisi tengkurap, sebuah bantal keras diletakkan di bawah perut untuk meregangkan/meluruskan 
punggung, dengan dahi bertumpu pada kedua punggung tangan, kepala pada posisi midline. Processus spinosus CV L5 diidentifikasi dengan melakukan palpasi dari sacrum ke kranial, processus spinosus CV L5 diidentifikasi sebagai suatu cekungan kecil yang tumpul pada pertengahan lumbosakral. Dengan menggunakan USG GE logic E9 kanalis spinalis lumbal diperiksa secara longitudinal dengan transducer 3,5 $\mathrm{MHz}$ langsung secara paramedial oblik dengan sudut 10-150 pada potongan sagittal. Pemeriksaan dilakukan pada sisi kanan spine. Pada monitor akan tampak echo lamina, anterior kompleks dan posterior kompleks, dimana kanalis spinalis merupakan ruang antara anterior kompleks dan posterior kompleks. Kanalis spinalis CV L3-L4, L4-L5, L5-S1 diukur dengan cara sedikit tilting ke medial dengan sudut +/- 10-15 ${ }^{\circ}$ untuk mengoptimalkan posterior dan anterior view. Untuk menghindari bias dalam pengukuran maka dilakukan penilaian oleh peneliti dan observer.

\section{HASIL DAN PEMBAHASAN}

Tabel 1 menunjukkan bahwa usia terbanyak kejadian nyeri punggung bawah berada pada umur 46-55 tahun (lansia awal) sebesar 12 sampel (37,5\%), 56-65 tahun yaitu 9 sampel $(28,1 \%)$, umur 26-35 tahun yaitu 6 sampel $(18,8 \%)$ dan umur $36-$ 45 tahun yaitu 5 sampel $(15,6 \%)$. Hal ini sesuai dengan teori dimana serangan pertama nyeri punggung bawah umumnya terjadi pada usia 30-50 tahun, dan nyeri punggung menjadi lebih sering dengan peningkatan usia. Berkurangnya kekuatan tulang akibat osteoporosis dapat meningkatkan risiko fraktur dan pada waktu yang sama elastisitas dan tonus otot menurun. Diskus intervertebralis mulai kehilangan cairan dan fleksibilitasnya, yang akan menyebabkan penurunan kemampuannya untuk melindungi tulang belakang. Risiko stenosis spinalis juga meningkat seiring peningkatan usia. $^{2}$

Tabel 1. Data karakteristik umum subyek penelitian

\begin{tabular}{lcc}
\hline & $\mathrm{N}$ & $\%$ \\
\hline Umur (tahun) & & \\
$26-35$ & 6 & 18,8 \\
$36-45$ & 5 & 15,6 \\
$46-55$ & 12 & 37,5 \\
$56-65$ & 9 & 28,1 \\
Jenis Kelamin & & \\
Laki-laki & 13 & 40,6 \\
Perempuan & 19 & 59,4 \\
\hline
\end{tabular}

Tabel 2. Penentuan Hasil Normal dan Stenosis Berdasarkan MR Myelografi

\begin{tabular}{ccccc}
\hline Level & Normal & $\%$ & Stenosis & $\%$ \\
\hline L3-L4 & 27 & 84,4 & 5 & 15,6 \\
L4-L5 & 21 & 65,6 & 11 & 34,4 \\
L5-S1 & 28 & 87,5 & 4 & 12,5 \\
\hline
\end{tabular}

Tabel 2 menunjukkan dari 20 sampel dengan stenosis didapatkan sebanyak 11 sampel (55\%) dengan stenosis pada level L4-L5, sebanyak 5 sampel (25\%) dengan stenosis pada level L3-L4 dan sebanyak 4 sampel (20\%) dengan stenosis pada level L5-S1. Hal ini sesuai dengan teori yang mengatakan bahwa kejadian stenosis kanalis spinalis lumbal paling banyak mengenai L4-L5 dan L3-L4. ${ }^{4}$

Dari tabel 3, hasil pemeriksaan MR myelografi ukuran thecal sac dengan stenosis L3-L4 yaitu 6,1 mm s/d 9,6 mm 
dengan mean 7,78 $\mathrm{mm}$; L4-L5 yaitu $5,4 \mathrm{~mm}$ $\mathrm{s} / \mathrm{d}$ 9,8 $\mathrm{mm}$ dengan mean 7,78 $\mathrm{mm}$; L5-S1 yaitu $6,2 \mathrm{~mm}$ s/d 9,4 $\mathrm{mm}$ dengan mean $8,52 \mathrm{~mm}$. Sedangkan ukuran thecal sac normal L3-L4 yaitu 10,3 mm s/d 17,2 mm dengan mean $12,77 \mathrm{~mm}$; L4-L5 yaitu 10,3 $\mathrm{mm} \mathrm{s} / \mathrm{d} 15,9 \mathrm{~mm}$ dengan mean $12,69 \mathrm{~mm}$; L5-S1 yaitu 10,2 $\mathrm{mm} \mathrm{s} / \mathrm{d} 16,8 \mathrm{~mm}$ dengan mean $11,68 \mathrm{~mm}$.

Tabel 3. Sebaran Hasil Ukuran Thecal Sac berdasarkan MR Myelografi dan Kanalis Spinalis Lumbal berdasarkan USG

\begin{tabular}{lccccccc}
\hline \multirow{2}{*}{ Diagnosis } & \multicolumn{3}{c}{ MR Myelografi (mm) } & \multicolumn{3}{c}{ Ultrasonografi $(\mathrm{mm})$} \\
& & Min-Max & Mean & SD & Min-Max & Mean & SD \\
\hline \multirow{2}{*}{ Stenosis } & L3-L4 & $6,1-9,6$ & 7,78 & 2,34 & $7,5-9,9$ & 8,30 & 2,25 \\
& L4-L5 & $5,4-9,8$ & 7,78 & 2,74 & $6,4-9,8$ & 8,32 & 2,56 \\
& L5-S1 & $6,2-9,4$ & 8,52 & 1,69 & $6,4-10,1$ & 8,92 & 1,65 \\
& L3-L4 & $10,3-17,2$ & 12,77 & 2,34 & $10,4-17,2$ & 12,77 & 2,25 \\
& L4-L5 & $10,3-15,9$ & 12,69 & 2,74 & $10,4-15,7$ & 12,87 & 2,56 \\
& L5-S1 & $10,2-16,8$ & 11,68 & 1,69 & $10,2-16,2$ & 11,95 & 1,65 \\
\hline
\end{tabular}

Hasil pemeriksaan ultrasonografi ukuran kanalis spinalis lumbal dengan stenosis L3L4 yaitu 7,5 $\mathrm{mm} \mathrm{s} / \mathrm{d}$ 9,9 $\mathrm{mm}$ dengan mean $8,30 \mathrm{~mm}$ dan SD 2,25 mm; L4-L5 yaitu 6,4 $\mathrm{mm} \mathrm{s} / \mathrm{d} 9,8 \mathrm{~mm}$ dengan mean $8,32 \mathrm{~mm}$ dan SD 2,56 $\mathrm{mm}$; L5-S1 yaitu $6,4 \mathrm{~mm} \mathrm{~s} / \mathrm{d}$ $10,1 \mathrm{~mm}$ dengan mean $8,92 \mathrm{~mm}$ dan SD 1,65 mm. Sedangkan ukuran kanalis spinalis lumbal normal L3-L4 yaitu 10,4 mm $\mathrm{s} / \mathrm{d} 17,2 \mathrm{~mm}$ dengan mean $12,77 \mathrm{~mm}$ dan SD 2,25 mm; L4-L5 yaitu 10,4 mm s/d 15,7 mm dengan mean $12,87 \mathrm{~mm}$ dan $2,56 \mathrm{~mm}$; L5-S1 yaitu $10,2 \mathrm{~mm} \mathrm{~s} / \mathrm{d} 16,2 \mathrm{~mm}$ dengan mean $11,95 \mathrm{~mm}$ dan SD 1,65 mm.

Tabel 4. Kesesuaian Pengukuran MR Myelografi dengan USG pada NPB

\begin{tabular}{ccc}
\hline Level & $p$ & $r$ \\
\hline L3-L4 & 0,001 & 0,985 \\
L4-L5 & 0,001 & 0,987 \\
L5-S1 & 0,001 & 0,973 \\
\hline
\end{tabular}

Pada tabel 4, setelah dilakukan pengolahan data dan uji Pearson menunjukkan bahwa terdapat kesesuaian antara hasil MR myelografi dengan ultrasonografi lumbosakral pada level L3-L4 dengan nilai p sebesar 0,001 $(<0,05)$ dan memiliki kekuatan hubungan kuat dengan nilai $r$ sebesar 0,985. Data juga menunjukkan bahwa terdapat kesesuaian antara hasil MR myelografi dengan Ultrasonografi lumbosakral pada level L4-L5 dengan nilai p sebesar 0,001 $(<0,05)$ dan memiliki kekuatan hubungan kuat dengan nilai $r$ sebesar 0,987. Data juga menunjukkan bahwa terdapat kesesuaian antara hasil MR myelografi dengan Ultrasonografi lumbosakral pada level L5-S1 dengan nilai p sebesar 0,001 $(<0,05)$ dan memiliki kekuatan hubungan kuat dengan nilai $r$ sebesar 0,973. Dari gambar 18 menunjukkan grafik MR myelografi dengan ultrasonografi saling berimpitan. Hal ini sesuai dengan penelitian sebelumnya Hulagu Kaptan dkk melaporkan pada pasien-pasien yang kanalis spinalis lumbal dengan diameter anteroposterior kurang dari $11,5 \mathrm{~mm}$, dipastikan stenosis kanalis 
spinalis lumbal, dan laminektomi total lebih sering dilakukan. ${ }^{15}$

Dari gambar 1 menunjukkan antara grafik MR myelografi dengan grafik ultrasonografi dimana antara grafik MR myelografi dan ultrasonografi lumbosakral saling berdekatan sehingga ini menunjukkan ada kesesuaian antara hasil MR myelografi dengan ultrasonografi lumbosakral.

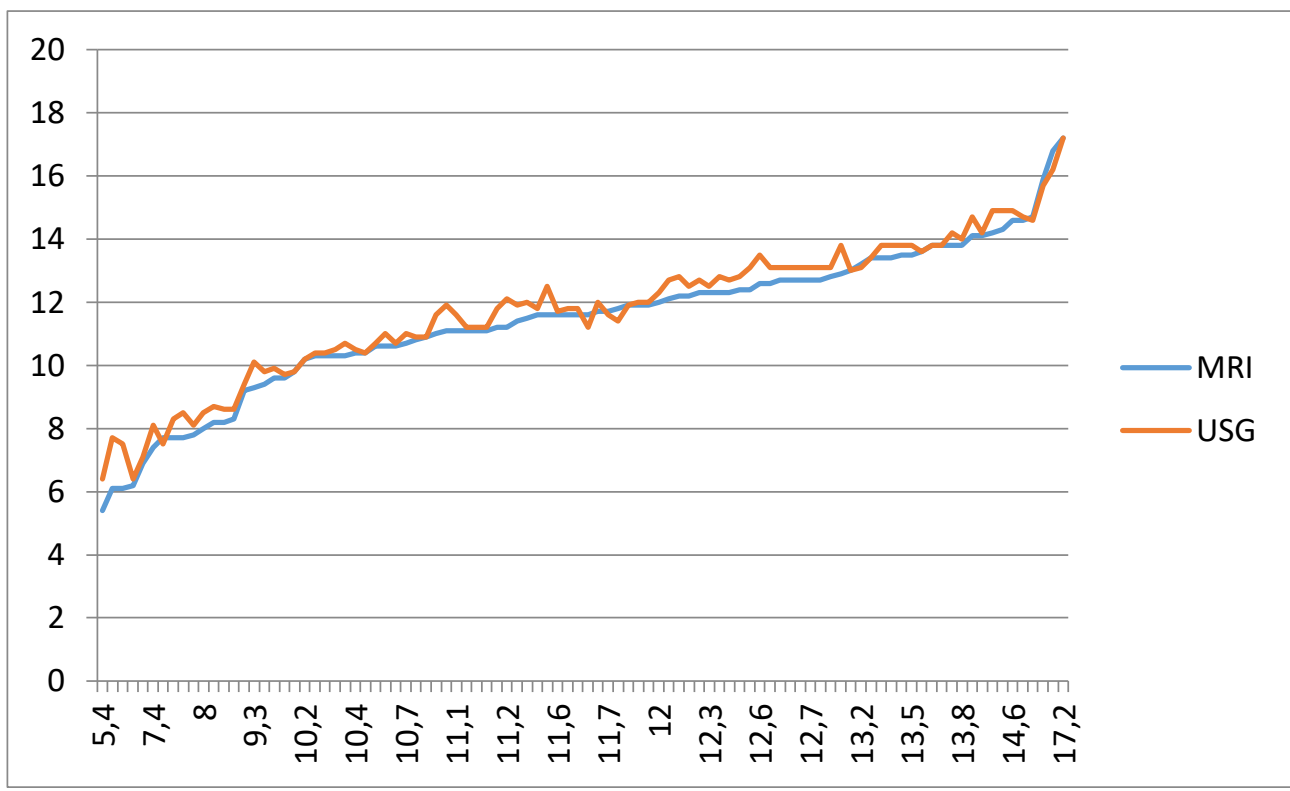

Gambar 1. Grafik kesesuaian pengukuran MRI-MR myelografi dengan USG pada penderita nyeri punggung bawah.

Penelitian ini juga sesuai dengan teori patoanatomi yaitu struktur anatomi yang bertanggung jawab terhadap penyempitan kanal adalah struktur tulang meliputi: osteofit sendi facet (merupakan penyebab tersering), penebalan lamina, osteofit pada korpus vertebra, subluksasi maupun dislokasi sendi facet (spondylolisthesis), hipertrofi atau defek spondylolysis, anomali sendi facet kongenital. Struktur jaringan lunak meliputi: hipertrofi ligamentum flavum (penyebab tersering), penonjolan annulus atau fragmen nucleus pulposus, penebalan kapsul sendi facet dan sinovitis, dan ganglion yang berasal dari sendi facet. Akibat kelainan struktur tulang jaringan lunak tersebut dapat mengakibatkan beberapa kondisi yang mendasari terjadinya lumbar spinal kanal stenosis, yaitu: degenerasi diskus, instabilitas segmental, hiperekstensi segmental dimana ketiga keadaan tersebut menyebabkan penyempitan kanal spinal lumbal (penurunan volume ruang) yang mengakibatkan kompresi saraf dan inflamasi elemen saraf. ${ }^{7}$

\section{SIMPULAN}

Terdapat kesesuaian ukuran kanalis spinalis lumbal berdasarkan ultrasonografi lumbosakral dengan MR myelografi lumbosakral pada penderita nyeri punggung bawah. 


\section{DAFTAR PUSTAKA}

1. Suharjanti I. Nyeri Punggung Bawah. Dalam: Suwondo BS, Meliala L, Sudadi, editors. Buku Ajar Nyeri [Internet]. Yogyakarta: Indonesian Pain Society. 2017. p.242-50. Diakses dari: [Link].

2. Aulina S. Anatomi dan Fisiologi. Dalam: Meliala L, Suryamihaja A, Purba JS, Sadeli HA, editors. Nyeri Punggung Bawah. Jakarta: Perhimpunan Dokter Spesialis Saraf Indonesia (PERDOSSI). 2003; 5-15.

3. Lubis I. Epidemiologi nyeri punggung bawah. Dalam: Meliala L, Suryamihaja A, Purba JS, Sadeli HA, editors. Nyeri punggung bawah. Jakarta: Perhimpunan Dokter Spesialis Saraf Indonesia (PERDOSSI). 2003; 1-3.

4. Fraser JF, Huang RC, Girardi FP, Cammisa FP. Pathogenesis, presentation, and treatment of lumbar spinal stenosis associated with coronal or sagital spinal deformities. Neurosurg Focus. 2003; 14(1):e6. [Abstract/FREE Full-Text]

5. Chin KJ, Karmakar MK, Peng P. Ultrasonography of The Adult Thoracic and Lumbar Spine for Central Neuraxial Blockade. Anesthesiology. 2011; 114(6): 1459-85. doi: 10.1097/ALN.0b013e318210f9f8.

6. Fortin JD, Wheeler MT. Imaging in Lumbar Spinal Stenosis. Pain Physician. 2004; 7(1):133-9. [Abstract/FREE Full-Text]

7. Siebert $\mathrm{E}$, Pruss $\mathrm{H}$, Klingebiel R, Failli V, Einhäupl KM, Schwab JM. Lumbar spinal stenosis: syndrome, diagnostics and treatment. Nat Rev Neurol. 2009; 5(7):392-403. doi: 10.1038/nrneurol.2009.90.

8. Fahy D, Nixon JE. (i) Lumbar Spinal Stenosis Current Orthopaedics. Current Orthopaedics. 2001; 15(2):91-100. doi: 10.1054/cuor.2001.0177.

9. Heidari P, Farahbakhsh F, Rostami M, Noormohammadpour P, Kordi R. The role of ultrasound in diagnosis of the causes of low back pain: a review of the literature. Asian J Sports Med. 2015; 6(1):e23803. doi: 10.5812/asjsm.23803.

10. Davies M. Spinal Canal Stenosis and Spondylolisthesis. Australian Doctor [Online]. 2010. Diakses dari: [Link]

11. Nagayama M, Watanabe Y, Okumura A, Amoh Y, Nakashita S, Dodo Y. High-Resolution Single-Slice MR Myelography. AJR Am J Roentgenol. 2002; 179(2):515-21. doi: 10.2214/ajr.179.2.1790515.

12. Eidelson SG. Spinal Stenosis Center. Spineuniverse [Online]. 2019. Diakses dari: [Link].

13. Forsberg L, Wallöe A. Ultrasound in sciatica. Acta Orthop Scand. 1982; 53(3):393-5. doi: 10.3109/17453678208992232.

14. Nadalo LA. Spinal Stenosis Imaging. Medscape [Online]. 2017. Diakses dari: [Link].

15. Kaptan H, Kasimcan O, Cakiroglu K, Ilhan MN, Kilic C. Lumbar Spinal Stenosis in Elderly Patients. Ann N Y Acad Sci. 2007; 1100:173-8. doi: 10.1196/annals.1395.015. 